Article

\title{
Implementing a Modern E-Learning Strategy in an Interdisciplinary Environment-Empowering UNESCO Stakeholders to Use Earth Observation
}

\author{
Tobias Matusch ${ }^{1, *}$, Anne Schneibel ${ }^{1}$, Lisa Dannwolf ${ }^{1}$ and Alexander Siegmund ${ }^{2}$ \\ 1 Research Group for Earth Observation, Department of Geography, Heidelberg University of Education, \\ Czernyring 22/11-12, 69115 Heidelberg, Germany; schneibel@ph-heidelberg.de (A.S.); \\ dannwolf@ph-heidelberg.de (L.D.) \\ 2 Research Group for Earth Observation, Department of Geography, Heidelberg University of Education \& \\ University Heidelberg, Czernyring 22/11-12, 69115 Heidelberg, Germany; siegmund@ph-heidelberg.de \\ * Correspondence: matusch@ph-heidelberg.de; Tel.: +49-6221-477-772
}

Received: 31 October 2018; Accepted: 20 November 2018; Published: 23 November 2018

check for updates

\begin{abstract}
The Copernicus Program and the fleet of available Earth observation satellites provide valuable services in sectors such as agriculture, forestry, urban monitoring, and heritage management. However, drawbacks such as knowledge gaps by the user, limited technical and financial facilities or the lack of ready-to-use data, result in insufficient exploitation of these opportunities by heritage site managers and other relevant stakeholders. Based on an initial assessment of current threats, existing limitations and potential applications, we developed the e-learning module Space2Place. Through the use of the learning module, stakeholders get a substantial introduction into Earth observation and knowledge barriers that may exist are removed. For this purpose, we refined an existing e-learning platform, which was developed in close relation to an online remote sensing application and adapted to the needs of UNESCO site stakeholders. One of the main features is the personalization of the learning modules content depending on the abilities or interests of the user. The platform offers information with different levels of difficulty and adaptable learning paths. A graduation certificate and practical exercises in an online remote sensing application increase the specific added value for UNESCO site manager. By using the associated remote sensing application and its link to Space2Place, heritage site managers also improve their knowledge on image processing by working with original satellite imagery. Additional advantages of using the platform will be enhanced through the introduction of new learning modules, translation into other languages and accompanying scientific research.
\end{abstract}

Keywords: e-learning; Earth observation; education; capacity development; cultural and natural heritage; UNESCO

\section{Introduction}

Education and learning approaches are changing dynamically in the course of time. Since the development of computer systems in the mid last century and through the spread of the internet, broadband access, and mobile phones, education systems changed tremendously [1]. Besides the challenges of a continuously changing educational landscape, e.g., with mobile learning and electronical learning application (hereafter e-learning), new approaches and technical opportunities offer a variety of new options for educational experts, teachers, and providers of education [2].

E-learning raised considerably in the past few years in quantity and quality [3]. The market is still booming with a compound annual growth rate of $7.5 \%$ up to a market volume of 275 Billion USD in 
2022 [4]. Promoting factors can be easily identified, ranging from flexibility in learning, accessibility and comparatively low costs [5]. Distance learning opportunities became more and more popular, also as a part of a whole distance learning program [1]. Nowadays, massive open online courses (MOOCs), often even free of charge, are accessible for an increasing global education market. Prominent MOOCs raised the attention of several thousand learners simultaneously, distributed all over the globe [6]. Free and open-source learning platforms for different topics were also established during the past years, altering academic structures and revenue models of the educational sector [7]. The large variety of available platforms and courses creates an offer, which might appear inscrutable for the respective learner. This is additionally challenging due to the lack of information about the effectivity and impact of an individual course. Many offers from the existing major platforms such as edX, Coursera or Udacity can provide useful information, but are not specifically tailored to the needs of heritage site managers and other relevant stakeholders. By providing concise e-learning modules adapted to the specific needs and in close relation with practical exercises in a simple remote sensing application, gained knowledge can be easily integrated in daily working routines. Additionally, a direct feedback and communication loop to the providers of the e-learning environment can mitigate inherent weaknesses of e-learning programs such as technical restrictions or limited interaction between teachers and peer-to-peers, which may have a negative impact on the effectiveness of e-learning courses [5].

Similar to the development in the field of computer systems and the e-learning sector, a boom in the field of remote sensing has emerged during recent years [8,9]. Satellite systems including GPS satellites, meteorological and communication satellite as well as Earth observation satellites constantly increase their socio-economic benefit for societies [10]. Geoinformatics and Earth observation applications are more and more part of our everyday life. Applications such as maps or navigation systems are, often unconsciously, even known by the youngest generation [11]. Benefit from Earth observation can be found in almost all areas of society and professions, including sectors such as agriculture, forestry, insurance, renewable energies, and air quality [10]. In addition, UNESCO stakeholders already benefit from the current development [12]. The magnitude of such a benefit depends considerably on the expertise, abilities, and received training on satellite image assessment of each individual [13]. UNESCO stakeholders are responsible for the management of designated UNESCO sites, which fall into three categories, including World Heritage Sites, Global Geoparks, and Biosphere Reserves, respectively. Currently, there are 1092 World Heritage Sites in total, 140 Global Geoparks, and 686 Biosphere Reserves [14-16], with varying cultural and natural assets, which currently also benefit quantitatively and qualitatively in very different ways from Earth observation. The work of UNESCO sites stakeholders can for example be facilitated by the monitoring of land cover changes [17], the surveillance of structural and ground deformation $[18,19]$ or the assessment of risks of natural and anthropogenic hazards [20-22].

However, Earth observation is still a field for experts and professionals with specific knowledge and experience [23]. This creates an entrance barrier for untrained students, the general public or pupils. Therefore, specialists and educational institutions are challenged to set-up entry points and lower the entry barriers. Many Earth observation specialists and users are not specifically experienced in computer sciences, but rather focused on natural and social sciences. Several initiatives were established in recent years, providing a hub for valuable information, serve as a starting point and provide opportunities to build professional networks. This includes initiatives e.g., organized by the European Space Agency (ESA) and associated with conferences on Earth observation (e.g., 3rd ESA-EARSeL course on remote sensing for archaeology) as well as specific activities on conservation of cultural and natural heritage such as the Digital Belt and Road (DBAR) Initiative, launched by the Institute of Remote Sensing and Digital Earth, Chinese Academy of Sciences. Despite these promising activities, which function as impulses, capacity development activities need to be broadly diversified. Accordingly, Earth observation industry and educational institutions need to adapt to the interdisciplinary field and face this challenge of educating an interdisciplinary group of actors. The varying research goals and objectives of different disciplines cannot be addressed with one unique 
approach. Accordingly, educational programs have the challenging task to bridge the gap between the users' relevant knowledge and the desired skills and capacities in Earth observation.

The presented e-learning strategy with the various applications are especially designed for an interdisciplinary community, in this case based on the needs of pupils of different grades. Integrated geographical topics are linked with remote sensing applications. The presented paper gives an overview about an e-learning system, which was especially designed for pupils and teachers. By adapting the course content and related methods, the e-learning module Space2Place attempts to empower UNESCO sites stakeholders to incorporate Earth observation into their working routines. The paper offers a detailed insight into the educational concept of the systems, its developing stages, and the technical framework conditions. The given details are supposed to contribute to the current debate on e-learning in the field of Earth observation. Furthermore, other actors should be encouraged to set up similar open source and barrier-free systems and improve the capacities of UNESCO stakeholders and other target groups in this sector.

\section{Materials and Methods}

The basis of the current e-learning system geospektiv (www.geospektiv.de, see Appendix A for further details of access), was developed in the framework of the project "Space4Geography" carried out between 2013 and 2017. The e-learning system has especially been designed for pupils, adolescent, and teachers in the context of secondary education. Its structure and content are based on a nationwide curricula analysis of the subject Geography in German high schools and secondary schools (www.rgeo. $\mathrm{de} / \mathrm{cms} / \mathrm{p} / \mathrm{bpa} /$ ). The federal states in Germany are primarily responsible for education, resulting in regional differences, e.g., in terms of temporal variations between the various topics [24]. Each of the learning modules is based on recent didactic research, partly conducted within the mentioned research project [25]. The modules offer a broad range of topics, some with focus on Germany (e.g., the Wadden Sea, Elbe flooding), but also from an international perspective (e.g., deforestation in the tropics, food security in Africa). The practical functions of the e-learning environment are based on the online remote sensing application BLIF (www.blif.de, see Appendix A further details of access). This educational software has been designed to improve the basic competences in the use of Earth observation with optical and radar sensors. Both websites have been operating together for about two years, resulting in important statistics, which were tracked by the website provider on general parameters and internal statistics. Analyses of these statistics are included in the results.

The technical infrastructure was developed in close cooperation with an external IT company, specialized in the design of websites and online platforms. In general, the e-learning system geospektiv and the online remote sensing application BLIF are two different platforms, but were developed on a common PostgreSQL database, joining the user groups of both platforms (see Figure 1). PostgreSQL itself is the standard open source relational database management system, developed by an independent community and is available free of charge. Users of the geospektiv homepage thus only need to register once. In this framework, the platform geospektiv is used for authorization and the administration of rights and user settings. Furthermore, specific statistics are tracked, and learning modules developed and stored. BLIF, on the other hand, is used to track the common users' records on remote sensing tools. This platform enables the users to administrate satellite imagery, or to upload and implement external imagery resources. Users and administrators have direct access to the BLIF and geospektiv back end, developed as a Pyramid web framework. As universally usable, Pyramid is based on the programming language Python, providing manifold opportunities from simple applications to complex web projects. From the back end, direct communication to the front end is possible, developed with html (Hypertext Markup Language) and JavaScript. Therefore, we used AngularJS, a web application framework for the client-side generation of the html website and to extent the related html vocabulary. Access is granted after authentication, whereby the system distributes the rights of the various user groups. The back end is running on a central server and provides necessary services e.g., for administrators, the illustration and functions of the site. The same 
applies to the connection between the BLIF front end and the BLIF back end. Geospektiv and BLIF offer a browser compatibility that is able to deal with the diverse technical requirements of common browsers such as Firefox, Chrome, Opera, and Safari. All browsers connect to the web server via the web addresses, which are in this case provided by Caddy. The web server Caddy is a http/2 web server, which automatically produces https (Hypertext Transfer Protocol Secure) sites. The http $/ 2$ is a further development of the former Hypertext Transfer Protocol (http), to optimize and accelerate the transmission between the specific user browser and the internet website. The https standard for a tap-proof transmission of data is an important requirement, especially when working with German educational and governmental institutions. The web server requests the relevant information from the web application framework, provided by AngularJS.

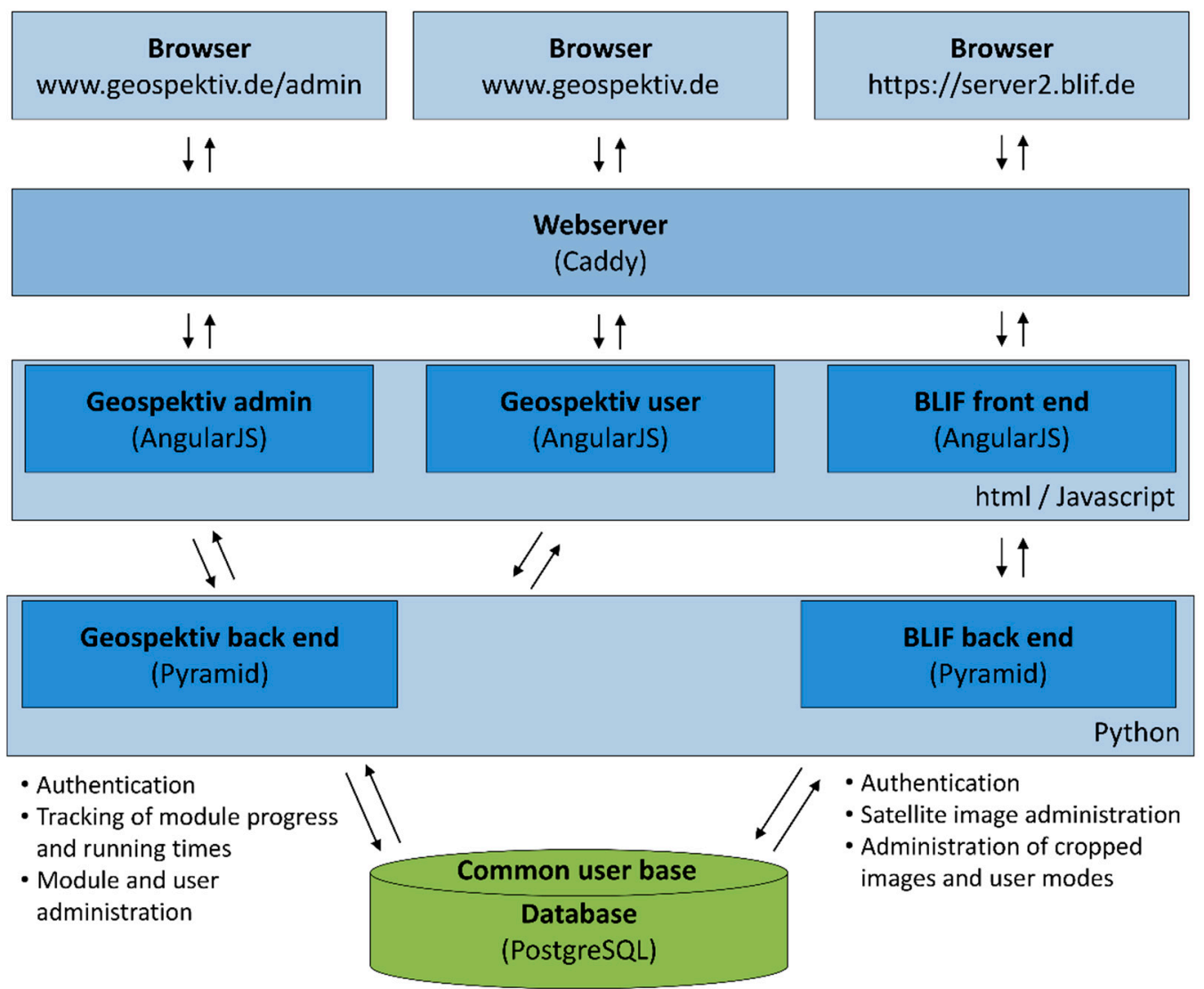

Figure 1. Technical structure of the e-learning environment with the most important functions and applications. An explanation of terms and acronyms can be found in Chapter 2.

The established software infrastructure is based on common, free accessible, and frequently used products. It is thus possible to copy the architecture and provide similar e-learning environments with own content or topics. However, the development relied on the strong technical expertise of the IT company. In particular, the fine-tuning and iterative adjustment steps increased additional costs and time expenditure considerably.

During an expert survey in 2017, the needs of UNESCO site managers regarding the potentials of Earth observation for the monitoring and management of UNESCO sites were recorded and will be presented in the results. By using Google forms, we received detailed feedback from 11 national and international experts. The majority of questions was posed in an open way, providing the opportunity for the experts to answer completely free and without limitations of specific categories. The results of the questionnaire were used for the design of Space2Place and the further development of geospektiv and BLIF. Of particular importance were the existing threats and the possible fields of application within the UNESCO sites. 
The aforementioned Space2Place is the final outcome of our activities, offering an e-learning module for adults to get a fundamental introduction into Earth observation and potential fields of applications. Based on the developed learning materials and methods shown above, the structure of Space2Place is described in detail in Section 3.3.

\section{Results}

For a better understanding of the strategy to empower UNESCO stakeholders, three distinct levels of results can be differentiated. The first level of results deals with the technical implementation of the e-learning system geospektiv. On the second level, results about the expert survey offering insights in current Earth observation usage practices of various institutions, current challenges and future potential are discussed. The third level of results describes the final Space2Place module, especially designed for the needs of UNESCO stakeholders and similar external experts. By combining these three distinct levels, the approach becomes clear and future potentials of the e-learning environment are apparent.

\subsection{Adaptive E-Learning System Geospektiv}

As explained in the previous chapter, the e-learning system is designed for pupils, based on a nation-wide curricula assessment. The high variety of different education formats in Germany on which the almost 11 million pupils are distributed show the demand for specifically adapted learning resources [26]. The implementation of Earth observation in German curricula aims at acquiring the ability to independently obtain, analyze and evaluate geographical information from aerial and satellite imagery. Accordingly, a competent interaction with digital Earth observation data is a prerequisite [11]. During the development of the platform, all learning modules were intensively evaluated by students and teachers in Germany. The various learning modules of geospektiv are based on different geographical questions. All learning modules are implemented in a capacity development program of the GIS-Station. Everybody can use these modules free of charge. However, the GIS-Station also offers assistance to give teachers and students a greater understanding of the modules and to promote their usability. New partner schools and teachers in general book a guided exercise through a pre-selected module to test the application and functionality. This often takes place in the facilities of the GIS-Station but is also possible through a set of iPads or laptops within the school itself. After completing a first module, teachers tend to use the e-learning function to conduct their courses independently with their school classes, in the framework of their lectures.

Notwithstanding the arrangement of the courses, geospektiv offers a range of advantages for teachers and pupils besides the integration of new techniques and interactive learning methods: (I) teachers can track the activity and results of every single student, also during the course. Thereby, the teacher can immediately offer help and support when necessary. (II) The e-learning system offers the possibility of adaptive learning and various learning paths are implemented in different modules, creating the opportunity for self-guided and self-paced learning.

The concept of adaptivity is provided in three optional ways. The first option is based on the selection of the user and his preferences (see Figure 2, box 4). At certain stages of the module, pupils and teachers can choose different paths they want to follow. Whether students want to find out more about the successful Landsat programme or the new Copernicus programme depends on their own decision. The second option is based on the number of points achieved within the intermediate tests and quizzes (see Figure 2, box 2). Pupils with higher scores receive more complex learning units according to their abilities. Pupils with lower scores receive easier units to create the opportunity for repetition and comprehension. The third option is based on timing. If pupils need more time to complete a quiz compared to a predetermined threshold value, they will receive easier learning units. This makes it possible for pupils that require more learning time to completely pass learning modules and share a feeling of success. Since all learning paths meet at the end and each pupil ends the module with the same concluding topic, the teacher can directly start the follow-up. Accordingly, 
personalization of modules allows for the promotion of gifted students and the support of students with existing knowledge deficiencies at the same time.

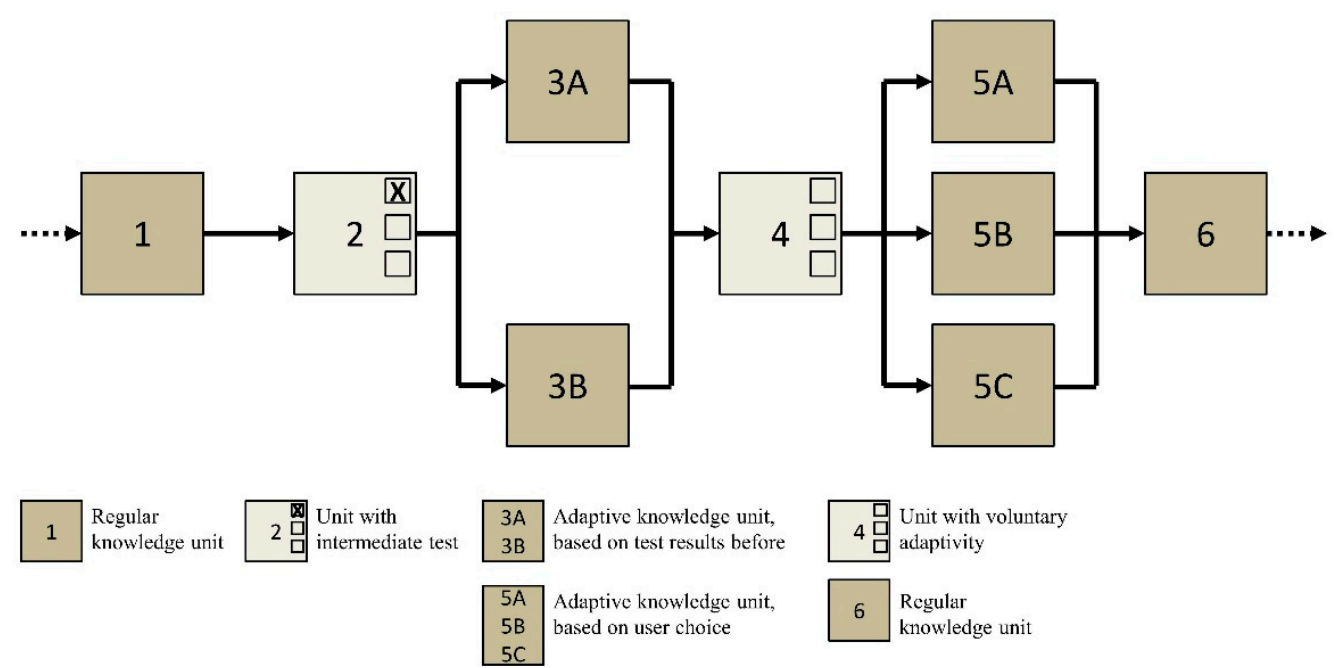

Figure 2. Adaptivity of the e-learning system with individual learning paths, based on score, time, and voluntary adaptivity.

Depending on the requirements and skills of the user, the e-learning system makes it possible to create modules with varying content and levels of difficulty. Currently available in geospektiv are four levels, which refer to German classes 5-6, 7-8, 9-10, and 11-13. The Organisation for Economic Co-operation and Development (OECD) offers an excellent overview of the different international education systems and various indicators within their reports through the interactive Education GPS $[27,28]$. Furthermore, there are numerous publications that present GIS technologies and their educational potentials in a pedagogical context. See for example Milson et al. (Eds.), who provide studies about the integration of GIS in education for several countries around the globe [29]. In geospektiv, an additional level has been designed for adults via Space2Place, creating off-the-job training opportunities. The duration of the modules is in general $90 \mathrm{~min}$, which temporarily refers to a double lesson in the German school system. It is not intended to use the modules autonomously out of regular school lessons. In fact, they should be used accompanying a thematic unit to generate new impulses and perspectives as well as to introduce the pupils to meaningful Earth observation applications. To keep the motivation and attention high during this period, the modules were designed to be interactive and multimedia content is also provided. The adaptive design of the system provides the opportunity that learning modules can be used inside and outside of the classroom with external devices such as tablets and smartphones. Furthermore, users have the freedom to choose their favorite operating system or browser. An overview of the distribution of used browsers, operating systems, and end devices in 2018 is shown in Figure 3. 


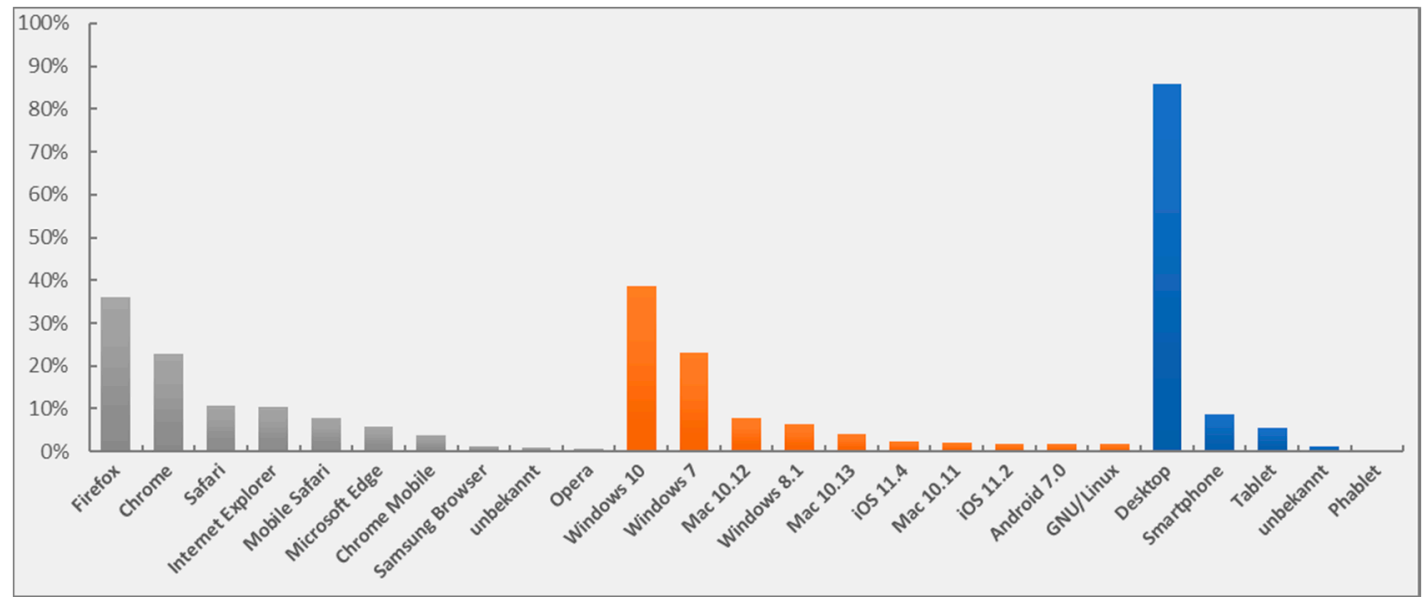

Figure 3. Percentage distribution of browsers (grey), operation systems (orange), and used end devices (blue) on the website geospektiv in 2018.

Results about the distribution partly reflect the current situation of IT infrastructure in German classrooms. Smartphones, tablet PCs, and wireless internet are only slowly being integrated [30]. The number of devices in schools is correspondingly low. The majority uses desktop PCs to access geospektiv (see Figure 4). Only a small proportion of participants use a smartphone or tablet to access geospektiv. However, the responsive web design was adopted to offer a flexible handling of the platform for the diverse devices. Both, smartphones and tablets, are represented with less than $10 \%$ of total users. This is in good accordance with the predestined use of the online remote sensing application BLIF, for which the major amount of information has been developed for desktop PCs.

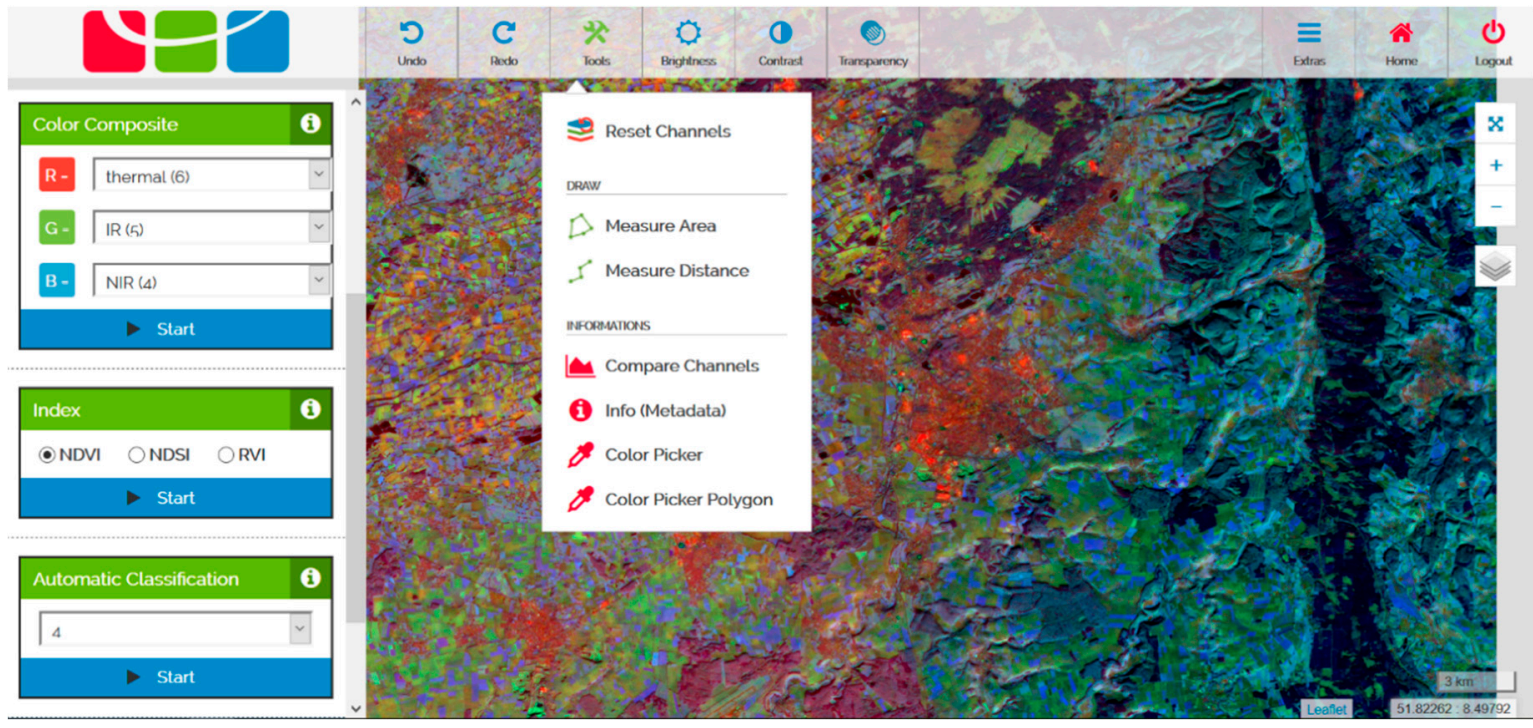

Figure 4. Graphical user interface (GUI) of the online remote sensing application BLIF, illustrating a false-color composite of a Landsat 5 image. On the left side, there are several available processing steps, above the picture some tools to evaluate the image.

Windows (incl. version 10 and 7) is the main operating system. However, also Mac, as operating system of Apple, with more than $10 \%$, is partly represented and thus almost identical with the market shares of the leading operating systems in Germany [31]. These figures show that for extensive usage, interoperability needs to be provided by an educational learning website as a critical factor. Even more widely spread is the use of common browsers, which is in good agreement to the current market shares of leading browsers in Germany, where Chrome, Firefox and the Internet Explorer are the most used 
browser [32]. For geospektiv in 2018, Firefox is leading with about 36\%, followed by Google Chrome with about $23 \%$, and Safari with $11 \%$. These three browsers cover only $70 \%$ of users. Especially the Internet Explorer as default browser on Microsoft operating systems and Microsoft Edge should not be neglected when dealing with educational websites for pupils and schools.

Independent of the used system or browser, all modules are based on a responsive design and provide immediate feedback to the user. Accordingly, pupils and teachers can use the feedback to reflect their learning progress and see what they have learned or where further repetition is necessary. The users can save their current status to interrupt and continue the module at any time. This allows, for example, the teacher to pause the module for additional interactions with the class. Of course, users also have the option of repeating certain learning units.

\subsection{Evaluation of the Expert Survey}

The expert survey, which was conducted before Space2Place was designed and established, gives a comprehensive insight into current applications of Earth observation as well as drawbacks in terms of the UNESCO-sites. Table 1 provides information about existing threats for UNESCO heritages sites, including biosphere reserves, main barriers for stakeholders to integrate Earth observation into working routines and how stakeholders perceive Earth observation to be beneficial for their respective individual organizations.

Table 1. Results of the expert survey, conducted at the beginning of 2017 with 11 experts coming from various institutions.

\begin{tabular}{|c|c|c|c|}
\hline Organization of the Expert & Specific Threats & Main Barriers & Beneficial Applications \\
\hline $\begin{array}{l}\text { UNESCO-associated } \\
\text { organization }\end{array}$ & $\begin{array}{l}\text { Manmade destruction } \\
\text { and war }\end{array}$ & Software usage & $\begin{array}{l}\text { Management of } \\
\text { UNESCO sites }\end{array}$ \\
\hline Governmental organization & $\begin{array}{c}\text { Urban development and } \\
\text { urban growth }\end{array}$ & Lack of knowledge & $\begin{array}{l}\text { Monitoring of changes, } \\
\text { impacts, and } \\
\text { interventions }\end{array}$ \\
\hline Free consultant & $\begin{array}{l}\text { Destruction and war, } \\
\text { natural disasters, climate } \\
\text { change, uncontrolled } \\
\text { human development, } \\
\text { tourism }\end{array}$ & $\begin{array}{l}\text { Work overload, inability } \\
\text { to handle data correctly }\end{array}$ & $\begin{array}{l}\text { Monitoring of land cover } \\
\text { changes, providing } \\
\text { accurate mapping, } \\
\text { detection of building } \\
\text { movements }\end{array}$ \\
\hline $\begin{array}{l}\text { Intergovernmental } \\
\text { organization }\end{array}$ & $\begin{array}{l}\text { Climate change, } \\
\text { shipping, oil and gas } \\
\text { exploration, tourism }\end{array}$ & $\begin{array}{l}\text { Unavailability of data, } \\
\text { interpretation and } \\
\text { ground-truth }\end{array}$ & $\begin{array}{c}\text { Long-term monitoring of } \\
\text { large areas }\end{array}$ \\
\hline UNESCO site & Intensive land use & Lack of time & $\begin{array}{l}\text { Updated information } \\
\text { base }\end{array}$ \\
\hline UNESCO site & & & $\begin{array}{l}\text { Monitoring without } \\
\text { aerial photography }\end{array}$ \\
\hline UNESCO site & $\begin{array}{c}\text { Intensification of } \\
\text { agriculture, } \\
\text { fragmentation and } \\
\text { habitat loss }\end{array}$ & $\begin{array}{c}\text { Unavailability of } \\
\text { ready-to use data, } \\
\text { already classified } \\
\text { datasets }\end{array}$ & Cost-efficiency \\
\hline NGO related to UNESCO & $\begin{array}{c}\text { Urban sprawl, renewable } \\
\text { energies }\end{array}$ & $\begin{array}{l}\text { Lack of time, } \\
\text { unavailability of data, } \\
\text { hard- and software } \\
\text { requirements, lack of } \\
\text { knowledge and } \\
\text { advantages }\end{array}$ & $\begin{array}{c}\text { Landscape monitoring } \\
\text { (i.e., urban sprawl or } \\
\text { cultivation of fallow } \\
\text { areas }\end{array}$ \\
\hline
\end{tabular}


Table 1. Cont.

\begin{tabular}{cccc}
\hline Organization of the Expert & Specific Threats & Main Barriers & Beneficial Applications \\
\hline Scientific institute & $\begin{array}{c}\text { Flooding and salt } \\
\text { intrusion }\end{array}$ & $\begin{array}{c}\text { Compromise between } \\
\text { large area and high } \\
\text { spatial resolution }\end{array}$ & $\begin{array}{c}\text { Planning of interventions } \\
\text { incl. vulnerable areas }\end{array}$ \\
Private company & $\begin{array}{c}\text { Vegetation growth and } \\
\text { vandalism }\end{array}$ & $\begin{array}{c}\text { Coarse spatial resolution } \\
\text { vavailability and } \\
\text { avoidance of field } \\
\text { investigations at } \\
\text { dangerous locations }\end{array}$ \\
\hline $\begin{array}{c}\text { Environmental protection } \\
\text { agency }\end{array}$ & Climate change & $\begin{array}{c}\text { Unavailability of ready } \\
\text { to use data }\end{array}$ & Larger spatial footprint \\
\hline
\end{tabular}

The diversity of institutions reflects the wide range of potential applications in the field of Earth observation and related sciences as well as educational backgrounds. The list of specific threats for UNESCO sites includes global challenges such as climate change and urban sprawl up to local phenomena such as the impact of manmade destructions including vandalism. The information of current barriers is sobering and reflects known drawbacks well [33,34]. Several times, the lack of ready-to-use datasets, missing users' knowledge, and technical requirements was mentioned. Since Earth observation is often simply a tool for UNESCO stakeholders to improve the management effectiveness of their sites, additional time for further education, besides the regular workload, is limited. Accordingly, the lack of time to implement new tools and workflows was mentioned a couple of times in the survey.

While the spatially precise mapping of large areas is also one of the key demands of stakeholders, the choice of the sensor must be based on its capability to capture the desired information in the observed environment [35]. The large variety of almost 100 available operating Earth observation satellites by the end of 2013 [9] with their high variability in different sensor specifications are due to the trade-off that has to be made between spatial, temporal and spectral resolution [36]. One of the key tasks of capacity development initiatives is thus to enable UNESCO site stakeholders to choose the appropriate Earth observation sensor with regard to their specific demands, the study time, and the size and location of the site to be observed. This also meets the stated demand of the stakeholders to improve the detection of impacts, the evaluation of interventions and the early detection of critical changes by using up-to-date information with high cost efficiency (Table 1).

The Copernicus is the most ambitious Earth observation program and it will be soon fully operational [30]. The freely available and free of charge datasets can be used in numerous applications. Therefore, we asked the experts about their awareness of the Copernicus program. The results, illustrated in Figure 5, show that the majority of respondents were not aware of the program, but consider that it can be useful for their organization. Especially UNESCO site stakeholders themselves seem to be less informed about the available Copernicus Earth observation data. Only about 1/3 already uses Copernicus data, which includes in particular private companies and UNESCO associated organizations. Only one respondent, an intergovernmental organization, answered that they know the Copernicus program, but that they are not relevant for their specific tasks. However, the cause for this specific answer could be a lack of information. 


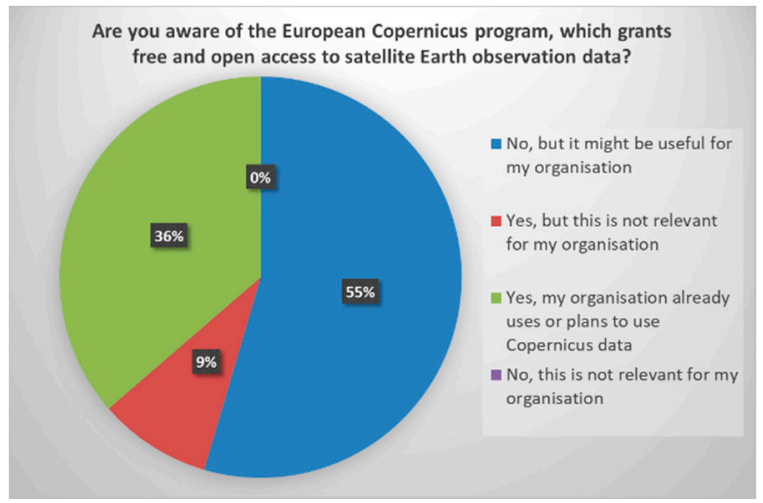

Figure 5. Awareness of the Copernicus program of interviewed experts at the beginning of 2017.

Accordingly, it is not surprising that Earth observation data is especially very often used in those organizations where the awareness about the Copernicus Program is equally high. About $60 \%$ of the interviewed experts use Earth observation data at least sometimes, reflecting the already high importance of these datasets in 2017. However, still four of eleven experts rarely use Earth observation data or not even at all (see Figure 6).

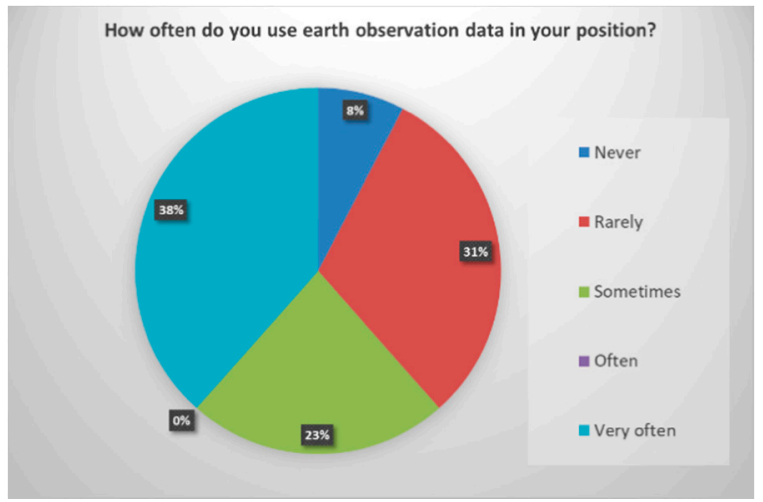

Figure 6. Frequency of EO data utilization of interviewed experts.

\subsection{The Space2Place Module}

The major aim of the learning module Space2Place is to empower UNESCO-site managers and planning authorities to incorporate data from the Copernicus programme into their daily working routines. Besides regular used very high resolution optical satellite images, current research also shows the potential of high resolution images such as Sentinel-2 images for the monitoring of cultural and archaeological sites [13]. By using practical examples and exercises, the capacities of stakeholders at UNESCO sites in the field of Earth observation should be enhanced. In addition to the general objective of integrating Earth observation applications into the daily working routines of UNESCO stakeholders, numerous intermediate objectives are useful. Space2Place should initially strengthen general knowledge and enhance the ability to communicate about Earth observation issues. This promotes the capacity to formulate needs and claim demands. The module was published online as an introductory course in Earth observation at the beginning of 2018.

The module consists of 21 learning units, including four intermediate tests and one final examination. Figures 7 and 8 give an impression of the usability of the GUI while Figures 9 and 10 show the usage of geospektiv and BLIF by students. Additionally, four links to the online remote sensing application BLIF are implemented. The module is designed for a duration of $120 \mathrm{~min}$ and registered users receive a graduation certificate at the end. The learning units are kept very broad to present an overview as large as possible. 


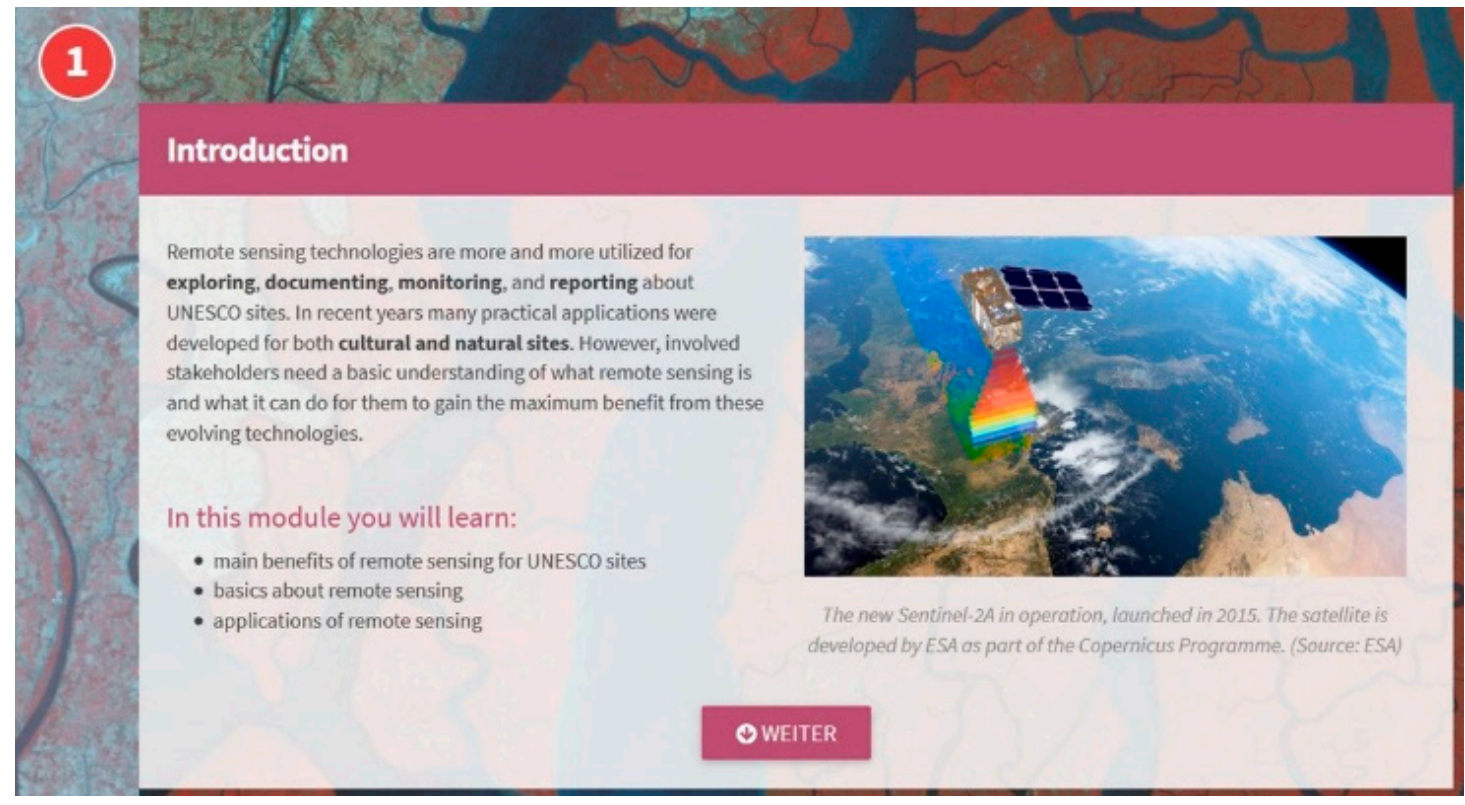

Figure 7. Front end of Space2Place and the first learning unit, introducing the learning module and giving a description of the learning objectives.

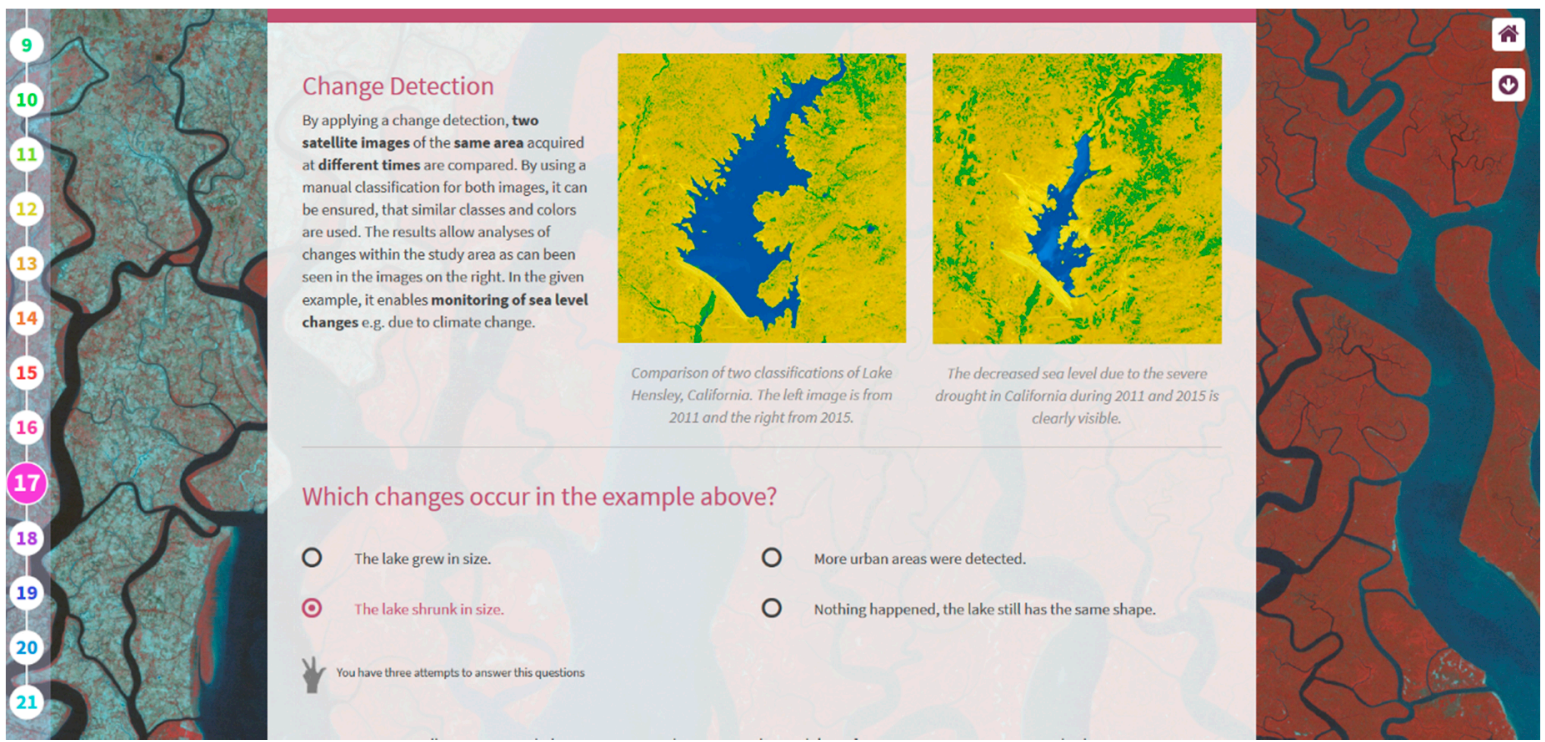

Figure 8. Graphical user interface of the learning module Space2Place, describing the change detection process with illustrations of the Lake Hensley in California. Below, a single choice test assesses the knowledge of participants. The results of this quiz and other quizzes are the basis for the evaluation on the final certificate. 


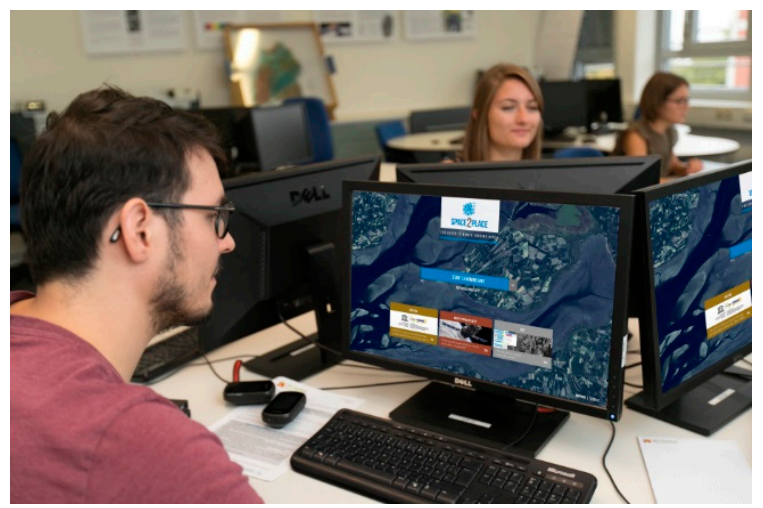

Figure 9. Students testing the learning module Space2Place in the premises of the GIS-Station. Under the guidance of a lecturer, the various processing steps and tasks are evaluated from a didactical point of view and with regards to the content.

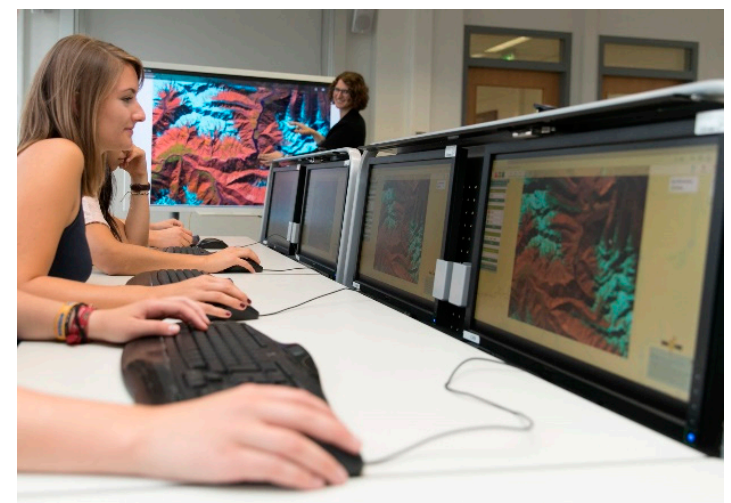

Figure 10. Students using the remote sensing application BLIF under the instruction of a lecturer. BLIF is integrated in all geospektiv modules and provides the basic functions to analyze remote sensing data.

Due to manifold applications and availability of data, a specific focus was placed on the Copernicus Program. Due to the different purposes of the satellites, various applications are possible, reflected by the Copernicus Services: Atmosphere, Marine, Land, Climate, Emergency, and Security. However, other data sources are also available within the module, providing the user with a wider spectrum of usable sensors such as Landsat and RapidEye. As a result, the integrated application examples are also kept without great detail, but will be specified for a deeper understanding by additional future learning modules.

\section{Discussion}

The developed learning module Space2Place is the result of ongoing activities and the high demand of capacity development and awareness raising for Earth observation applications in the context of UNESCO-sites and the SDGs [37]. Especially since the UNESCO signed various conventions on the use of space technologies in 2007 to strengthen monitoring activities of world heritage sites, these aspects have gained importance [38-40]. As shown above, various applications such as for example on natural disasters and natural hazards, like flooding already available to facilitate the work of UNESCO-site stakeholders [21,22]. The potential negative impacts of the predicted climate change will probably increase the necessity of an operational monitoring [41]. Applications on radar satellites to monitor movements of single buildings or small-scale unites in a range of $\mathrm{cm}$ or even $\mathrm{mm}$ will probably be introduced in the future $[18,19]$. Additionally, the use of Sentinel-2 images offers various possibilities for monitoring UNESCO sites, which are e.g., affected by armed conflicts and crises [13]. Another useful source of information are InSAR products and related knowledge, which can be utilized by the stakeholders to improve their management and monitoring strategies [42]. 
On the other hand, a variety of shortcomings limited the desired impact and widespread participation of UNESCO site stakeholders on the technological progress through Earth observation. Accordingly, educational programs are challenged by the variety of educational backgrounds and intended purposes by the UNESCO stakeholders. Clearly, such multifaceted challenges cannot be overcome by a standardized online education program alone. The developed Space2Place learning module and further modules which will follow should act as initial starting points for individual users, also to refer to other more advanced and specific offers. The setting in geospektiv and BLIF allows the handling of both, optical and radar satellite images, covering the needs of a broad range of users. A distinction into different e-learning modules for cultural heritage sites, often optimally studied with radar data and natural heritage sites, which are often best observed with optical data, is therefore not necessary. A smooth transition between different sensors, which can often be used in practice, is feasible and necessary for an educational program covering the diverse UNESCO heritage sites.

As other studies show, maintenance and technical support of the e-learning platform is of major importance [5]. According to the user statistics of geospektiv and written feedback, users are quickly frustrated and show little understanding, if technical errors appear regularly or even permanently and thus reduce the performance of the website. Furthermore, the rapid development in the Earth observation sector requires regular adjustments and adaptation to the changing data availability. Since the beginning of May 2018, BLIF offers the opportunity to incorporate Sentinel-2 satellite images, possible via a connection to the German Copernicus data and exploitation platform CODE-DE (https:// code-de.org/), which is also the access point for information products of Copernicus services.

Ideally, e-learning offers should be supplemented by classroom events and face-to-face training. Especially during the winter season, an increase in e-learning activities as indoor classroom activities can be recorded. Particular emphasis should be placed on accompanying learning to enable direct interaction between pupils, tutors and teachers. This also promotes social skills and communication capabilities of pupils. By embedding external courses into classroom activities and the regular curricula, cross-thematic and interdisciplinary approaches are encouraged. Nevertheless, focusing on didactical aspects, distance and e-learning approaches also have numerous weaknesses. This includes e.g., often a limited interaction with the teacher and other participants, decreasing motivation and technical problems. There are also numerous obstacles in the field of didactics. This includes the disparate perception of male and female users in dealing with e-learning programs [43,44]. More research is necessary to implement these differences in current and future e-learning offers.

A blended learning strategy seems also more promising for UNESCO site stakeholders than mere distance learning. Such approaches provide the opportunity to implement interactive inputs in face-to-face trainings, opportunities for peer-to-peer networking, and the exchange on a peer-to-peer level. These networks are not only important to increase the effectivity of learning, but also for the daily working routines in managing UNESCO sites.

Various factors support the use of the e-learning modules and the remote sensing application BLIF:

1. Personalization of learning paths based on the adaptive design of the website is probably the most important factor for the application of geospektiv and Space2Place. By promoting fast learning users and support slow learners, more efficient learning outcomes can be realized [45].

2. A crucial point is the award in terms of a graduation certificate by the end of each learning module. In various countries, such certificates are part of the necessary prerequisites for job promotions or financial compensations. Regardless of the content, the expected final certificate additionally stimulates the brain's reward system, increases the motivation and reduces the rate of termination during the modules [46].

3. Another important factor is the security of the website, especially if it is used in an educational context in Germany. To control the access to forbidden websites or undesired changes in the system, considerable restrictions on computers and networks are often set by administrators. Accordingly, the website needs to be secured by https to be accessed, which is in the case of 
geospektiv and BLIF automatically provided by Candy. However, this also requires that only secure content is implemented in the learning modules, otherwise no https security can be provided by the system.

4. The language barrier is another crucial factor, often resulting in a reduced understanding of the learning units. Space2Place is currently offered in English to meet the standard in the global education system. New courses will also initially be offered in English upon introduction. The online remote sensing application BLIF is additionally available in German, French and Italian as well as in Spanish soon. The e-learning platform geospektiv will be soon available in Spanish as well, next to the default languages of German and English.

UNESCO was an active partner during the adoption of the SDGs and creation of the sustainable development agenda [47]. UNESCO sites are important places for learning and creating opportunities to implement sustainable development. Earth observation and its application can significantly contribute to the 2030 Agenda as well as to monitor the progress for certain indicators [48]. Knowledge sharing and education activities on an international level are necessary to facilitate the process of implementing Earth observation data into working routines of heritage site stakeholders [48]. By trying to fill the existing gaps in knowledge of site managers and other relevant stakeholders related to the potentials of Earth observation, the offered e-learning environment can contribute to the preservation of our heritage sites. Despite useful operating instructions and the help of user descriptions from the internet, many of today's remote sensing software packages are still very complex and cluttered, especially for non-experts and users with less experience. The offered learning platform and online remote sensing application does not claim to be complete, but serves as an easy and barrier-free entry point into the field of Earth observation. Not all users will be transferred into Earth observation experts, but the gained knowledge will enhance understanding about the Earth observation technology and support the decision-making process.

By offering an e-learning platform, we can not only foster the use of Earth observation in general and impart knowledge to the different stakeholders, but also address various SDGs and contribute to the 2030 Agenda. One important aspect is the existing gender gap and under-representation of women in STEM (science, technology, engineering and mathematics). This aspect is closely related to the quality of education (SDG 4), gender equality (SDG 5) and the reduction of inequalities (SDG 10) as important objectives of the United Nations. Several studies show that distant learning approaches can minimize the existing gender gap and provide useful education opportunities for women [5,49]. Accordingly, there is an urgent need to implement results of known studies about the differences of male and female in participation of e-learning courses [43,44]. By integrating relevant results, geospektiv and Space2Place can also assist to close the gender gap and promote women in STEM fields.

\section{Conclusions and Outlook}

The e-learning environment including geospektiv and BLIF is constantly under development and expansion. New language packages will be added in the medium-term future. This includes the platform itself, but also the translation of learning modules into other languages. The focus is on translations into English, but courses with content in Spanish and French will follow. Accompanying scientific research and evaluations set the focus in two areas. The first one concentrates on the difference between pupils and adults, the second focus is on the mentioned gender gap and difference in learning types between male and female.

New learning content in line with state-of-the-art didactical research will be added and a practical introduction with didactic preparation will be made available. By using different cooperation, further contact persons can be introduced to refer the UNESCO site stakeholders accordingly. This will extend the network of stakeholders and lead to valuable linkages with Earth observation experts. 
Author Contributions: The first author T.M. made the following contributions: Conceptualization; Formal analysis; Investigation; Methodology; Project administration; Software; Validation; Visualization; Writing-original draft; Writing-review \& editing. A.S. (Anne Schneibel) as second author contributed to the paper as follows: Validation; Visualization; Writing-original draft; Writing-review \& editing. As third author L.D. made significant contributions to the following fields: Methodology; Software; Validation Writing-review \& editing. A.S. (Alexander Siegmund) as fourth author contributed to: Conceptualization; Funding acquisition; Supervision

Acknowledgments: This research was partially supported by German Aerospace Center (DLR), due to the project funding of Space4Geography (50 RO 1301). Furthermore, we would like to thank the GIS-Station, Klaus-Tschira-Centre of Competence for digital Geo-media, for providing insights and expertise that greatly assisted the research. Additionally, we like to thank ebene fünf $\mathrm{GmbH}$ for technical support.

Conflicts of Interest: The authors declare no conflict of interest.

\section{Appendix A}

Geospektiv (www.geospektiv.de) and BLIF (https://server2.blif.de/login) are freely available for everyone. Interested users can access the websites and create an account by registering. They automatically receive user rights as a teacher, which makes it possible to create group records for single classes and to monitor the learning progress of individual students. Any questions or feedback is possible through the contact e-mail address given in the websites. A member of the rgeo team takes care of processing the request. In future video tutorials, the user will be guided through the remote sensing software and the most important functions will be explained.

\section{References}

1. Arkorful, V.; Abaidoo, N. The role of e-learning, advantages and disadvantages of its adoption in higher education. Int. J. Instr. Technol. Distance Learn. 2015, 12, 29-42.

2. El-Hussein, M.O.M.; Cronje, J.C. Defining Mobile Learning in the Higher Education Landscape. J. Educ. Technol. Soc. 2010, 13, 12-21.

3. Fallon, C.; Brown, S. e-Learning Standards-A Guide to Purchasing, Developing, and Deploying Standards-Conformant E-Learning; CRC Press: Boca Raton, FL, USA, 2016.

4. Orbis Research. Global E-Learning Market Research Report and Forecast to 2017-2022 (Report). Retrieved from Statistics MRC. Available online: www.reuters.com/brandfeatures/venture-capital/article?id=11353 (accessed on 23 November 2018).

5. Welsh, E.T.; Wanberg, C.R.; Brown, K.G.; Simmering, M.J. E-learning: Emerging uses, empirical results and future directions. Int. J. Train. Dev. 2003, 7, 245-258. [CrossRef]

6. The 50 Most Popular MOOCs of All Time 2018, Online Course Report. Available online: https://www. onlinecoursereport.com/the-50-most-popular-moocs-of-all-time/ (accessed on 22 November 2018).

7. Peters, M.A. Technological unemployment: Educating for the fourth industrial revolution. Educ. Philos. Theory 2017, 49, 1-6. [CrossRef]

8. Schreier, G.; Dech, S. High resolution earth observation satellites and services in the next decade-A European perspective. Acta Astronaut. 2005, 57, 520-533. [CrossRef]

9. Belward, A.S.; Skøien, J.O. Who launched what, when and why; trends in global land-cover observation capacity from civilian earth observation satellites. ISPRS J. Photogramm. Remote Sens. 2015, 103, 115-128. [CrossRef]

10. PricewaterhouseCoopers International. Copernicus Market Report-November 2016. In Study to Examine the Socio-Economic Benefits of Copernicus in the EU; PricewaterhouseCoopers International: Luxembourg, 2016.

11. Ditter, R. The Effectiveness of Digital Learning Paths in Remote Sensing-An Empirical Study of Secondary School Students' Learning based on Motivation and Self-Concept; Pädagogische Hochschule Heidelberg: Heidelberg, Germany, 2014.

12. Negula, I.D.; Sofronie, R.; Virsta, A.; Badea, A. Earth Observation for the World Cultural and Natural Heritage. Agric. Agric. Sci. Procedia 2015, 6, 438-445. [CrossRef]

13. Tapete, D.; Cigna, F. Appraisal of Opportunities and Perspectives for the Systematic Condition Assessment of Heritage Sites with Copernicus Sentinel-2 High-Resolution Multispectral Imagery. Remote Sens. 2018, 10, 561. [CrossRef] 
14. UNESCO. UNESCO World Heritage Centre-World Heritage List. Available online: http:/ /whc.unesco. $\mathrm{org} /$ en/list/ (accessed on 24 January 2018).

15. UNESCO. UNESCO Global Geoparks । United Nations Educational, Scientific and Cultural Organization. Available online: http:/ / www.unesco.org/new/en/natural-sciences/environment/earth-sciences/unescoglobal-geoparks / (accessed on 24 January 2018).

16. UNESCO. Biosphere Reserves_Learning Sites for Sustainable Development 2017; United Nations Educational, Scientific and Cultural Organization: Paris, France, 2017.

17. Giri, C.; Pengra, B.; Zhu, Z.; Singh, A.; Tieszen, L.L. Monitoring mangrove forest dynamics of the Sundarbans in Bangladesh and India using multi-temporal satellite data from 1973 to 2000. Estuar. Coast. Shelf Sci. 2007, 73, 91-100. [CrossRef]

18. Tapete, D.; Cigna, F. InSAR data for geohazard assessment in UNESCO World Heritage sites: State-of-the-art and perspectives in the Copernicus era. Int. J. Appl. Earth Obs. Geoinf. 2017, 63, 24-32. [CrossRef]

19. Zhou, W.; Chen, F.; Guo, H. Differential Radar Interferometry for Structural and Ground Deformation Monitoring: A New Tool for the Conservation and Sustainability of Cultural Heritage Sites. Sustainability 2015, 7, 1712-1729. [CrossRef]

20. Hadjimitsis, D.; Agapiou, A.; Alexakis, D.; Sarris, A. Exploring natural and anthropogenic risk for cultural heritage in Cyprus using remote sensing and GIS. Int. J. Digit. Earth 2013, 6, 115-142. [CrossRef]

21. Wang, J.-J. Flood risk maps to cultural heritage: Measures and process. J. Cult. Herit. 2015, 16, $210-220$. [CrossRef]

22. Joyce, K.E.; Belliss, S.E.; Samsonov, S.V.; McNeill, S.J.; Glassey, P.J. A review of the status of satellite remote sensing and image processing techniques for mapping natural hazards and disasters. Prog. Phys. Geogr. Earth Environ. 2009, 33, 183-207. [CrossRef]

23. Wang, L.; Ma, Y.; Yan, J.; Chang, V.; Zomaya, A.Y. pipsCloud: High performance cloud computing for remote sensing big data management and processing. Future Gener. Comput. Syst. 2018, 78, 353-368. [CrossRef]

24. Fuchsgruber, V.; Schütt, F.; Viehrig, K.; Wolf, N.; Siegmund, A. Thematische und regionale Schwerpunkte in deutschen Bildungsplänen-Eine bundesweite Vergleichsstudie für das Fach Geographie an Gymnasien. Prax. Geogr. 2017, 3, 54-56.

25. Wolf, N.; Fuchsgruber, V.; Riembauer, G.; Siegmund, A. An Adaptive Web-based Learning Environment for the Application of Remote Sensing in Schools. ISPRS Int. Arch. Photogramm. Remote Sens. Spat. Inf. Sci. 2016, XLI-B6, 53-56. [CrossRef]

26. Destatis. Schülerzahlen im Schuljahr 2017/2018 um 0.4\% Zurückgegangen; Destatis—Statistisches Bundesamt: Wiesbaden, Germany, 2018.

27. OECD. Education GPS; OECD Publishing: Paris, France, 2018.

28. OECD. Education at a Glance 2018: OECD Indicators; OECD Publishing: Paris, France, 2018.

29. Milson, A.J.; Demirci, A.; Kerski, J.J. International Perspectives on Teaching and Learning with GIS in Secondary Schools; Springer: Dordrecht, The Netherlands, 2012; ISBN 978-94-007-2120-3.

30. Bos, W.; Lorenz, R.; Endberg, M.; Eickelmann, B.; Kammerl, R.; Welling, S. Schule Digital_Der Länderindikator 2016 Kompetenzen von Lehrpersonen der Sekundarstufe I im Umgang Mit Digitalen Medien im Bundesländervergleich; Waxmann Verlag: Münster, Deutschland, 2016; ISBN 978-3-8309-3540-7.

31. Destatis. Marktanteile der Führenden Betriebssysteme in Deutschland von Januar 2009 bis September 2018; Destatis-Statistisches Bundesamt: Wiesbaden, Germany, 2018.

32. Destatis. Marktanteile der Führenden Browserfamilien an der Internetnutzung in Deutschland von Januar 2009 bis September 2018; Destatis-Statistisches Bundesamt: Wiesbaden, Germany, 2018.

33. Rose, R.A.; Byler, D.; Eastman, J.R.; Fleishman, E.; Geller, G.; Goetz, S.; Guild, L.; Hamilton, H.; Hansen, M.; Headley, R.; et al. Ten ways remote sensing can contribute to conservation: Conservation Remote Sensing Questions. Conserv. Biol. 2015, 29, 350-359. [CrossRef] [PubMed]

34. Turner, W.; Spector, S.; Gardiner, N.; Fladeland, M.; Sterling, E.; Steininger, M. Remote sensing for biodiversity science and conservation. Trends Ecol. Evol. 2003, 18, 306-314. [CrossRef]

35. Woodcock, C.E.; Strahler, A.H. The factor of scale in remote sensing. Remote Sens. Environ. 1987, 21, 311-332. [CrossRef]

36. Townshend, J.R.G.; Justice, C.O. Selecting the spatial resolution of satellite sensors required for global monitoring of land transformations. Int. J. Remote Sens. 1988, 9, 187-236. [CrossRef] 
37. Paganini, M.; Petiteville, I.; Ward, S.; Dyke, G.; Steventon, M.; Harry, J.; Kerblat, F. Satellite Earth Observation in Support of the Sustainable Development Goals; European Space Agency: Paris, France, 2018.

38. Hernandez, M.; Huth, U.; Schreier, G. Earth Observation from Space for the Protection of UNESCO World Heritage Sites: DLR Assisting UNESCO. In Proceedings of the International Archives of the Photogrammetry, Remote Sensing and Spatial Information Sciences, Beijing, China, 3-11 July 2008; pp. 643-646.

39. Stewart, C.; Rast, M.; Sarti, F.; Arino, O. ESA Activities in Earth Observation for Cultural Heritage Applications. Int. J. Herit. Digit. Era 2015, 4, 325-338. [CrossRef]

40. UNESCO. Agreement between UNESCO and the United States National Aeronautics and Space Administration (NASA) for Cooperation on World Heritage Conservation, Monitoring of Biosphere Reserves and Natural Hazards, and Space Earth Science Education, Capacity-Building, and Outreach Activities 2005; UNESCO: Paris, France, 2005.

41. Reimann, L.; Vafeidis, A.T.; Brown, S.; Hinkel, J.; Tol, R.S.J. Mediterranean UNESCO World Heritage at risk from coastal flooding and erosion due to sea-level rise. Nat. Commun. 2018, 9, 4161. [CrossRef] [PubMed]

42. Pastonchi, L.; Barra, A.; Monserrat, O.; Luzi, G.; Solari, L.; Tofani, V. Satellite Data to Improve the Knowledge of Geohazards in World Heritage Sites. Remote Sens. 2018, 10, 992. [CrossRef]

43. Wehrwein, E.A.; Lujan, H.L.; DiCarlo, S.E. Gender differences in learning style preferences among undergraduate physiology students. Adv. Physiol. Educ. 2007, 31, 153-157. [CrossRef] [PubMed]

44. Ong, C.-S.; Lai, J.-Y. Gender differences in perceptions and relationships among dominants of e-learning acceptance. Comput. Hum. Behav. 2006, 22, 816-829. [CrossRef]

45. Klašnja-Milićević, A.; Vesin, B.; Ivanović, M.; Budimac, Z.; Jain, L.C. Personalization and Adaptation in E-Learning Systems. In E-Learning Systems; Springer International Publishing: Cham, Switzerland, 2017; Volume 112, pp. 21-25. ISBN 978-3-319-41161-3.

46. Grimes, P.M.; Grimes, L.S.; Grimes, C.M. Method and System for Integrated Reward System for Education Related Applications. U.S. Patent 14/213,928, 19 September 2014.

47. UNESCO. UNESCO Moving Forward the 2030 Agenda for Sustainable Development; United Nations Educational, Scientific and Cultural Organization: Paris, France, 2017.

48. Anderson, K.; Ryan, B.; Sonntag, W.; Kavvada, A.; Friedl, L. Earth observation in service of the 2030 Agenda for Sustainable Development. Geo Spat. Inf. Sci. 2017, 20, 77-96. [CrossRef]

49. Cuadrado-García, M.; Ruiz-Molina, M.-E.; Montoro-Pons, J.D. Are there gender differences in e-learning use and assessment? Evidence from an interuniversity online project in Europe. Procedia Soc. Behav. Sci. 2010, 2, 367-371. [CrossRef]

(C) 2018 by the authors. Licensee MDPI, Basel, Switzerland. This article is an open access article distributed under the terms and conditions of the Creative Commons Attribution (CC BY) license (http://creativecommons.org/licenses/by/4.0/). 